\title{
A Research on Question Traction Teaching Method in the Teaching Reform of "Aeronautical Material Science"
}

\author{
Nie Xiangfan, He Weifeng, Li Yuqin, Yang Zhufang \\ Science and Technology on Plasma Dynamics Lab. \\ Air Force Engineering University \\ Xi'an, China \\ skingkgd@163.com
}

\author{
Chen Cuiling \\ Xinqiao Adult \& Community School \\ Shanghai, China \\ shangdiancui@126.com
}

\begin{abstract}
In the "Aeronautical Material Science" curriculum, there are some typical features, such as too many concepts, few inference, complex and abstract concepts, as well as difficult to understand. In order to promote students' enthusiasm and interest and improve their studying efficiency and quality, a new teaching method of "Question Traction Teaching" is proposed by positive exploring. Detailed reflections are as following: carding knowledge system of every lesson and setting some questions skillfully, connecting knowledge points by the logical relationship among all the questions. At last, knowledge can be visualized by specification-driven abstraction. Through new teaching method, there as some benefits to students' studying, such as stimulating interest, guiding pre-class study, improving understanding ability, accepting efficiency on class, and accelerating memorization and consolidation of knowledge points. Question Traction Teaching method can guarantee high teaching efficiency, enhance teaching quality, and develop students' initiative and creative ability simultaneously.
\end{abstract}

Keywords-Aeronautical Material Science; Question traction teaching method; Teaching efficiency and quality; Practical example; Practical achievements

\section{INTRODUCTION}

Science \& technology of aeronautical materials is the important field, which every country all over the world is developing preferentially and contending intensely. It becomes the vital part of national security strategy. At present, aeronautical material is developing into high performance, integration of structure and function, intelligence and low cost. The function of our university, Air Force Engineering University, is training professional military officers on use and maintain of aero equipment for Air Force of China, and "Aeronautical Material Science" is the professional basic course in the specialty of aircraft and power engineering [1]. Facing to the quick development of aeronautical materials during the progress of teaching the use and maintain of aero equipment to students, how to improve the efficiency of teaching and studying "Aeronautical Material Science" become a key problem we should solve immediately. Therefore, according to the course features of "Aeronautical Material Science", we should follow its development demand tightly, insist on students' dominant role and teachers' leading role, and carry on educational reformation and innovation actively [2]. Through bringing in the Question Traction Teaching Method into the daily teaching activities, some actual beneficial effects have been implemented on the aspects of improving cultivation quality, operational ability, innovative ability and scientific thought of undergraduates [3].

\section{Course feAtures of “AERONAUTICAL MATERIAL SCIENCE"}

"Aeronautical Material Science" is a professional basic course, and an applied laboratory course which regards both theory and practice as equally important. It can punning basic knowledge for the subsequent professional courses, and play a connecting action in the specialty system. The course refers to basic theory which is microscope and abstract. The course contains many terms, concepts, tables and techniques. Therefore, it is very hard for students to master all the knowledge of aeronautical materials. In addition, the course is a complex specialty of physics, chemistry, mechanics and material, and there some special features, such as broad knowledge, massive contents, strong practicality and tight connection with active aero equipment. The above features make a big trouble for teaching this course and students always encounter many problems, which leads to an unexpected result for some students.

\section{QUESTION TRACTION TEACHING METHOD}

According to the above course features of "Aeronautical Material Science", we propose the Question Traction Teaching Method (QTTM) by drawing typical teaching methods and advanced experience at home and abroad. Some researches in education psychology have indicated that students' thought always begin in question, and develop during solving the question [4]. Therefore, if we make some skillful questions as traction, students will think about the reasons and discuss with others. On this basis, they will try to seek for the answers, analyze the feasibility, and obtain the best solution. At last, scientific solution and effective implement results can be obtained. Through the question solving process, students' 
thought can be trained, and learning interest can be motivated [5]. In addition, students will be accelerated to think and create, and deepen the understanding of the set questions during discussing. And then the creative consciousness and ability will be improved significantly. The above description is basic thought of question traction teaching method.

The key of question traction teaching method is leading students to participate into the whole teaching activity [6]. The students are turned from knowledge passive receivers into knowledge active creators, and their autonomic studying activity can be aroused completely [7]. In this way, students can think autonomously and study with others by teaching efficiency enhancement and potential development. Finally, a new teaching model will be formed, in which the students' concepts, knowledge, ability and methods can be transformed into the quality for success.

\section{PRACTICAL EXAMPLE OF QUESTION TRACTION TEACHING METHOD}

In order to understand the Question Traction Teaching Method, an example of stainless steel lesson is as following. The lesson of stainless steel contains many contents, such as concept, types, chemical components, properties, application, problem and solving methods. As we see, there are so many knowledge points that students are hard to understand and master completely.

\section{A. Setting the questions before class}

According to the detailed contents of stainless steel lesson, we can set some questions, such as why corrosion happens in steel, how to prevent corrosion, why stainless steel can prevent corrosion, what is typical stainless steel, where stainless steel applied in aeronautic, what problems often happen and how to solve. This questions should be set corresponding to the important knowledge points. In addition, these questions can arouse students' learning interest and guide them to study by themselves. Through these questions, they can clearly understand the logical relationship preliminary, where stainless steel comes from, what stainless steel is and where stainless steel goes.

\section{B. Solving the questions on class}

On class, teachers should teach the related knowledge points by solving the questions one by one, and the order of questions should not be changed, because the order is just the logical relationship and knowledge system. Teaching in this special order is better for students to under the knowledge points. In details, the question of why corrosion happens in steel leads students to under the phenomenon and the principle of corrosion, chemical corrosion and electrochemical corrosion in the common steel. The question of how to prevent corrosion introduces the general ways to prevent corrosion, such as protection film, single phase and alloy elements. The question of what is typical stainless steel make students know that the stainless steel is obtained by mixing some alloy elements into the common steel, such as $\mathrm{Cr}, \mathrm{Ni}, \mathrm{Mo}, \mathrm{Mn}, \mathrm{Cu}$, and so on. The question of where stainless steel applied in aeronautic tells students that stainless steel is mainly used in the aircraft covering, pipes and compressor blades. The question of what problems often happen and how to solve indicates that the intercrystalline corrosion often happens in austenite stainless steel, resulting in cracks and fracture. There are three effective solution ways for preventing intercrystalline corrosion, solution treatment, lower carbon content and mixing the alloy elements of $\mathrm{Ti}$ and $\mathrm{Nb}$.

\section{Recalling the questions after class}

After class, it is not necessary for students to remember all the knowledge points. They just recall all the questions mentioned on the class, and try to think about the answers. Moreover, try to connect all the questions and answers, and then find the relationship among them. Through above procedures, the main important knowledge points can be remembered further and structure system will be established in their mind. The knowledge as a whole system is easier to remember and harder to forget. Especially, the question of what problems often happen and how to solve is very useful for guiding the practical work after graduation, which is the skill for students to dispose actual breakdown problems in the aeronautic equipment.

\section{IMPLEMENTATION SITUATION OF QUESTION TRACTION TEACHING METHOD}

In order to put the teaching reformation thought and detailed processes into practice, we should pay more attention to the advanced contents and open problems on the aspect of teaching contents [8]. The teaching effects benefit teachers as well as students by the active interaction between teachers and students.

(1) The relevant questions should be told to students when the last lesson is over. The questions should be set according to the important teaching points and curriculum standards. In addition, the questions should be practically significant with the combination of theory and facture. During the implementation process, students are divided into many groups, and very group should collect related information and read references to try to answer the questions as a team. Then, students can propose their opinions and doubts after thinking about the questions. The key of setting questions is that simple question draw forth complex question, experimental phenomenon draw forth important concept and engineering background draw forth theory question. Through this way, the teaching can be extended from class to out-of-class, and the aim of improving students' self-learning ability can be achieved.

(2) In order to meet the demand of undergraduate teaching, we should give a clear learning vein, and require students to finish the learning task in the specified time. We tease the course knowledge by discussion, retain the backbone contents and highlight the key points. The key of introducing Question Traction Teaching Method into classes is the whole control of teacher, and the teacher leading students to discuss the questions. Especially, when teaching the material of typical aeronautic materials in the aero equipment, the first step is that we should analyze the cause of the actual service problem of aeronautic materials and gasp the main factors. Students are 
divided into groups to analyze the factors and propose solving schemes respectively, and they should also prove the feasibility of all the schemes. Only in this way, the best solving scheme can be chose. The second step is that we should discuss the best scheme further by the mastered theory and method, do some experiments to verify. If the experiment results are consistent with the related theory, we can say the scheme is the best and is what we want. Students complete the logical derivation of important knowledge points by the chained question discussion, deepen the learning of knowledge points, master the related knowledge points successfully and improve their learning ability.

(3) If we can use some research examples of aeronautic materials, the teaching efficiency of Question Traction Teaching Method can be improved to a higher step. Reinforce the pertinence and usability of question discussion by the factual examples, which can clear-out students' analysis directions further. By means of taking example by successful cases, students' consciousness and ability of innovation by themselves will be improved. Such as the lesson of super alloy, the discussion tasks of alloying principle, using environment and part design are arranged. These discussion tasks can increase the atmosphere of exploration and thinking, and leading students to think in different ways. The thought extension is good for discovering innovation potentials and arousing innovation vitality, which is also good for evoking students' learning atmosphere.

(4) In order to make an adequate thinking space for students, teachers should pay more attention to teaching of every conclusions and discussion part. Then, we carry out the discussion, and lead students to think, learn, research. So, we prevent the situation that teacher says too much, but students just listen and don't want think. The teaching activity is not the performance of the teacher. In opposite, the students are the main part of teaching and should participate in the teaching activity completely. Only student master the knowledge by participation, we can say that this lesson is a good lesson and this course is a good course, because the target of teaching is just disseminating knowledge.

(5) The practical achievements of Question Traction Teaching Method should be guaranteed by arranging experiments and training in scientific design method. After the discussion on questions on class, we should arrange some related experimental lessons to intensify the practice features of teaching methods. Then, the mastering degree of important knowledge points will be improved, and students' operation ability will be enhanced [9].

\section{TEACHING ACHIEVEMENTS OF QUESTION TRACTION TEACHING METHOD}

\section{A. Broadening students' knowledge scope}

Students are inspired to carry on autonomic and creative thinking by setting open questions, and then their interests can be aroused. In order to seek for answers, students read many references and think about the questions seriously, and their knowledge scope extends gradually. In addition, they can also understand some interesting stories about famous scientists and emulate the scientists' scientific spirit, and then the target of educating people can be realized. Under the leading of teacher, students thick about the questions deeply, and discuss with others. Through thinking and discussion, students have deeper and clearer understanding about aeronautic materials development and application. Students feel commonly that their cognition for professional knowledge has transformed from ignorance into clearness, and their knowledge scope has extended largely. With the help of Question Traction Teaching Method, students can more easily master the core contents, which play an acceleration action for the subsequent course studying.

\section{B. Knowledge visualization by materialization the abstracted contents}

As for the course of "Aeronautic material science", students often feel boring and hard, because of the complex concepts and less logical knowledge points. Therefore, how to arouse students' studying interest is very important. In addition, how to improve students' studying initiative and lead students to knowing to learn, liking learning and grad to learn, is also very important, which every educator should think about [10]. On the class, design series of questions according to important knowledge points, and put forward consciously. Then, the knowledge transfers during the process of thinking and discussing. Question trigger discussion, and discussion deepen thinking, and finally visual knowledge are obtain by thinking. In this method, the teacher's leading action and students' dominant role are organically combined, so the communication is reinforced between teacher and students. Above all, the question is solved in the discussion, and cognition is improved in the thinking.

\section{CONCLUSIONS}

The course of "Aeronautic Materials Science" should focus on the improvement of students' comprehensive quality and the effective training of students' innovation spirit and ability. Through studying this course, students should adjust to the rapid development of aeronautic materials, and satisfy for the manpower demand of air force in the aeronautic materials field. Therefore, we should explore actively for the reformation of teaching methods during the teaching process of this course. We guarantee the teaching efficiency by introducing the question traction method. Develop students' activity and creativity at the same time of tamping teaching quality, and then the adequately combination of students' autonomic learning, cooperative learning and explorative learning can be realized. Finally, the teaching and studying efficiency will be improved significantly. 


\section{ACKNOWLEDGMENT}

The question traction teaching method was proposed under the guidance of Professor Li and Professor Kang. Thanks for their suggestions on the detailed implementation and overall plan. In addition, thanks the university government for the supports on course policy and teaching conditions.

\section{REFERENCES}

[1] Jinxing Kang, Kangmin Ma. “Aeronautic Materials Science," Beijing: National Defence Industry Press, 2013. (In Chinese)

[2] Zhangwen Zhou, Dongye Yao, Zhufang Yang. "The teaching reform and practice of aircraft \& engine engineering speciality," Journal of Higher Education Research, 2012, 35(3): 98-99. (In Chinese)

[3] Yuqin Li. "The Teaching Method of Discussion Deriving from Questions," Education Teaching Forum, 2016, 49(12): 206-207. (In Chinese)

[4] Jianfeng Zhang. "How to carry out problem-based teaching," Journal of Yanbian Institute of Education, 2009, 23(4): 107-108. (In Chinese)

[5] Xiaoyan Gao. "Creation and reformation of problem-based teaching model," Chinese higher education, 2008, 24: 43-44. (In Chinese)

[6] Qiang Wu, Yu Gao. "Reflections on inquiry-oriented teaching of basic technology course," Journalof Nanjing University of Science and Technology, 2012, 25(1): 82-86. (In Chinese)

[7] Yongqiang Liu, Mei Lin, Xiaolu Zhang. "Exploration and Research of Heuristic Teaching," The Science Education Article Collects, 2013 , 245(6):29-30. (In Chinese)

[8] Haojun $\mathrm{Xu}$, Li Cheng, Dongliang Liu. "The New Research of the Undergraduate Innovative Teaching in Aviation Maintenance Engineering in Military Academies," 2009, 32(3): 63-65. (In Chinese)

[9] Li Ye, Wang Cuixiang, Ji Zhengzhou, Wang Qian, Miao Zheng. "Constrction of practical teaching system to high-quality and applied undergraduates," 2011, 16(S2): 78-81. (In Chinese)

[10] Tian Xinhua, Wang Weina. "Increasing the teaching quality by strengthening the teaching research," Journal of Xi'an Eurasia University, 2008, 6(4): 62-64. (In Chinese) 